\title{
USO DE FLUXOFENIM EM TRIGO COMO PROTETOR AO HERBICIDA S-METOLACHLOR
}

\author{
J.R.V. Silva ${ }^{1}$, D. Martins, ${ }^{1}$ A.C. Cataneo ${ }^{2}$, J.V.C. Silva ${ }^{3}$, L.C. Ferreira ${ }^{2}$, G.S.F.Souza ${ }^{1}$, C.C. Martins $^{1}$ \\ ${ }^{1}$ Universidade Estadual Paulista, Faculdade de Ciências Agronômicas, Departamento de Produção Vegetal, \\ Setor Agricultura, Rua José Barbosa de Barros, 1780, CEP 18603-970, Botucatu, SP, Brasil. E-mail: joão.vaz@ \\ syngenta.com
}

\begin{abstract}
RESUMO
Este trabalho teve o objetivo de avaliar a eficiência do protetor fluxofenim no tratamento de sementes de trigo, cultivar Ônix, para o aumento da seletividade do herbicida S-metolachlor aplicado em pré-emergência e determinar a atividade da enzima de detoxificação glutationa S-transferase (GST). O trabalho foi realizado em duas etapas: a primeira para a avaliação em campo da eficiência do protetor em reduzir sintomas visuais de fitointoxicação causados pelo herbicida, e a segunda para a determinação da atividade da GST, conduzida em laboratório. Os tratamentos utilizados foram: aplicação ou não do protetor na dose de $40 \mathrm{~mL}$ por $100 \mathrm{~kg}$ de sementes e a pulverização do herbicida S-metolachlor nas doses de 1.440 e $2.880 \mathrm{~mL}^{\text {i.a.ha }}{ }^{-1}$, além de uma testemunha sem aplicação, sendo que, na determinação da atividade da GST, se excluiu o tratamento com aplicação de $2.880 \mathrm{~mL}$ i.a.ha ${ }^{-1}$ de S-metolachlor. Foram comparadas a suscetibilidade ao herbicida por meio da avaliação visual de injúrias aos 3, 7, 15 e 30 dias após a emergência (DAE) e a massa seca de raiz e parte aérea aos 10 DAE. Para a determinação da atividade da GST foram coletadas amostras da parte aérea das plantas aos 15 dias após a aplicação dos tratamentos e aos 10 DAE. Apesar do fluxofenim utilizado no tratamento da cultivar de trigo conferir uma maior tolerância ao herbicida S-metolachlor, ocorreu fitointoxicação visual e redução do estande de plantas. A cultivar testada apresentou aumento na atividade da enzima GST quando da utilização do fluxofenim anteriormente à aplicação do herbicida S-metolachlor na dose de $1.440 \mathrm{~mL}$ i.a. ha ${ }^{-1}$.
\end{abstract}

PALAVRAS-CHAVE: Pré-emergência, S-tranferase, Triticum aestivum.

\section{ABSTRACT}

FLUXOFENIM APPLIED ON WHEAT AS A SAFENER FOR PROTECTION AGAINST SMETOLACHLOR HERBICIDE. This work aimed to evaluate the effectiveness of fluxofenim used for seed treatment as safener in wheat, Ônix cultivar, treated with the herbicide S-metolachlor applied in pre-emergence. The study was divided in two steps. The first step consisted of an evaluation of fluxofenim's safener potential for the reduction of visual symptoms of S-metolachlor injury in the field, and the treatments were S-metolachlor at 1,440 and 2,880 mL i.a. ha- ${ }^{-1}$ and fluxofenim at 0 , and $40 \mathrm{~mL}$ per $100 \mathrm{~kg}$ of seeds, and a control without herbicide. The second step was to evaluate glutathione S-transferase activity (GST). Herbicide phytotoxity was measured by way of visual symptoms at 3, 7, 15, and 30 days after emergence (DAE), dry matter from roots and leaves at 10 DAE. For the determination of GST activity, the canopy of plants was collected at 10 DAE and 15 days after treatment application. The wheat presented low tolerance to S-metolachlor at both rates, and fluxofenim increased S-metolachlor selectivity to wheat but not sufficiently, reducing plant population to a nonacceptable level. Gluthationa S-transferase activity for wheat increased when seeds treated with fluxofenim were submitted to S-metolachlor at 1,440 $\mathrm{mL}$ a.i. ha ${ }^{-1}$.

KEY WORDS: Pre-emergence, S-transferase, Triticum aestivum..

\section{INTRODUÇÃO}

O controle químico de plantas daninhas é, sem dúvida nenhuma, o método de manejo mais adotado pelos produtores agrícolas de alta tecnologia, seja pela eficiência dos produtos ou pela facilidade da utilização. Dentre os herbicidas de aplicação em pré-emergência há o S-metolachlor, que pertence ao grupo das acetanilidas e, apesar de ter sido amplamente estudado, não tem seu mecanismo de controle totalmente conhecido (WEED..., 1994). É interessante esclarecer, contudo, que os herbicidas

${ }^{2}$ Universidade Estadual Paulista, Instituto de Biociências, Departamento de Química e Bioquímica, Botucatu, SP, Brasil. ${ }^{3}$ Universidade Federal de Uberlândia, Departamento de Produção Vegetal, Uberlândia,MG, Brasil. 
seletivos atuam como agentes de seleção da composição específica das comunidades infestantes. Em regiões de monocultura e anos sucessivos de utilização dos mesmos produtos haverá uma alteração de flora, predominando aquelas espécies tolerantes aos produtos empregados, podendo ser selecionadas espécies tolerantes ou biótipos resistentes (PITELLI, 1987), como são os caso da ocorrência, em áreas de cana-de-açúcar, no Estado de São Paulo, de plantas do gênero Digitaria com maior tolerância a alguns herbicidas (DiAs et al., 2005) e da buva (Conyza bonariensis) resistente ao glyphosate na região sul do Brasil (VARGAs et al., 2007).

Um dos mecanismos que conferem resistência ou tolerância às plantas daninhas é a metabolização do herbicida, que ocorre quando a planta resistente ou tolerante possui a capacidade de decompor a molécula herbicida mais rapidamente do que as plantas sensíveis, tornando-a inativa. As formas mais comuns incluem hidrólise ou oxidação, das quais surgem grupamentos adequados para conjugação com glutationa (GSH) e aminoácidos (KREUZ et al., 1996).

As glutationa S-transferases (GST) são consideradas como enzimas de desintoxicação e de fato foram primeiro descobertas por sua capacidade de metabolizar uma ampla variedade de compostos exógenos tóxicos (xenobióticos), via conjugação com glutationa (MANNERVIK; DANIELSON, 1988; Hess; Weller, 2000). Outros conjugados são movidos para o vacúolo por transportadores do tonoplasto dependentes de ATP, denominados bombas GS X ou transportadores ABC ("ATP binding cassette").

Protetores ou 'safeners' (também conhecidos como antídotos) são agentes químicos, com habilidades únicas, utilizados para reduzir a intoxicação das plantas por herbicidas através de um mecanismo fisiológico ou molecular, sem interferir no controle de plantas daninhas (HATZIOS, 1983). Mudanças significativas no aumento da tolerância de algumas culturas conferida pelos protetores à utilização de certos grupos químicos de herbicidas podem ser alcançadas tanto através do uso do protetor no tratamento de sementes, como em mistura ao ingrediente ativo do herbicida aplicado em pós ou pré-emergência através de um produto comercial único.

O uso dos protetores na agricultura, apesar de efetivo, é muito específico e o sucesso para sua utilização é encontrado somente em algumas espécies de gramíneas, não tendo nenhum efeito que diminua a injúria dos herbicidas para culturas dicotiledôneas. O fluxofenim é usado comercialmente como protetor na cultura do sorgo em alguns países e seu uso leva a uma redução na intoxicação do herbicida S-metolachlor à cultura (SYNGENTA, 2002).

Os protetores também aumentam os níveis de glutationa (GSH) intracelular. Isto poderia ser uma resposta do estresse ou ser devido a uma influência mais direta sobre as enzimas envolvidas na síntese da glutationa (FARAGO; BRUNOLD, 1990), no qual a elevação da GSH resultante poderia desempenhar um papel na indução de GSTs (MAUch; DudLER, 1993). O aumento das taxas de conjugação da GSH aos herbicidas aplicados na cultura pode aumentar a velocidade e a eficácia do processo de desintoxicação dos herbicidas nas plantas (JABLONKAI; HATZIOS, 1991; TAL et al., 1993; RIECHERS et al., 1996; CATANEO et al., 2003; Nemat Alla et al., 2007; Nemat Alla et al., 2008).

O presente trabalho teve como objetivo estudar o efeito da utilização do fluxofenim como protetor e sua interação quando da aplicação de diferentes doses do herbicida S-metolachlor, bem como seu reflexo sobre a atividade da enzima glutationa Stranferase na cultivar de trigo Ônix.

\section{MATERIAL E MÉTODOS}

O trabalho foi conduzido em duas etapas: a primeira realizada em campo para avaliar visualmente as plantas quanto à intoxicação causada pela aplicação do herbicida S-metolachlor e do protetor fluxofenim nas sementes de trigo, e a segunda foi realizada em laboratório para quantificar a enzima glutationa S-transferase.

Os experimentos para avaliação de injúrias foram conduzidos e avaliados no Município de Uberlândia, MG. O solo do local é classificado como Latossolo Vermelho Amarelo e sua análise física apresentou: $36 \mathrm{~g} \mathrm{~kg}^{-1} \mathrm{de}$ areia grossa, $69 \mathrm{~g} \mathrm{~kg}^{-1}$ de areia fina, $270 \mathrm{~g}$ $\mathrm{kg}^{-1}$ de silte, $624 \mathrm{~g} \mathrm{~kg}^{-1}$ de argila e, a química: M.O. = $3,1 \mathrm{dag} \mathrm{kg}^{-1}, \mathrm{pH}=6,4, \mathrm{~V} \%=75 \mathrm{e} \mathrm{SB}=59 \mathrm{mmol}_{\mathrm{c}} \mathrm{dm}^{-3}$.

A cultivar de trigo testada foi a Ônix. O experimento foi disposto em esquema de parcelas subdivididas, tendo como tratamento principal a aplicação do herbicida S-metolachlor (Dual Gold ${ }^{\circledR}$ ) nas doses de $0,1.500$ e $3.000 \mathrm{~mL} \mathrm{ha}^{-1}$, dispostas em blocos ao acaso, com três repetições e, como tratamento secundário, a aplicação ou não do protetor fluxofenim (Concep ${ }^{\circledR}$ ) - 0 e $40 \mathrm{~mL}$ por $100 \mathrm{~kg}$ sementes (Tabela 1 ). Foram semeadas 60 sementes por metro a $5 \mathrm{~cm}$ de profundidade e a adubação utilizada no plantio foi feita com $400 \mathrm{~kg}$ ha-1 da fórmula NPK 8-28-16.

Cinco horas antes da aplicação do S-metolachlor foi realizada uma irrigação de $30 \mathrm{~mm}$ e, durante a condução do experimento, duas vezes por semana foi realizada irrigação $(30 \mathrm{~mm})$. As parcelas experimentais foram constituídas por 6 linhas e as subparcelas compostas por 3 linhas tratadas com protetor e 3 linhas sem o tratamento, espaçadas de $0,7 \mathrm{~m}$ por $3 \mathrm{~m}$ de comprimento.

O tratamento de sementes com fluxofenim, na dose de $40 \mathrm{~mL}$ p.c. por $100 \mathrm{~kg}$ sementes, foi realizado no dia anterior a semeadura. A aplicação do herbi- 
cida S-metolachlor foi realizada em pré-emergência, nas dosagens de $1.500 \mathrm{~mL} \mathrm{ha}^{-1}$ e $3.000 \mathrm{~mL} \mathrm{ha}^{-1}$ utilizando-se um pulverizador costal pressurizado a $\mathrm{CO}_{2}$, equipado com 6 pontas jato plano XR $11002 \mathrm{VS}$, espaçadas de 0,5 m e com pressão de trabalho de 2,82 bar. O volume de calda de pulverização foi de 200 $\mathrm{L} \mathrm{ha}^{-1}$. As condições climáticas durante a aplicação dos tratamentos químicos foram: URar $(\%)=68, \mathrm{~T}=$ $26,1^{\circ} \mathrm{C}$ e a velocidade do vento $=0,8 \mathrm{~km} \mathrm{~h}^{-1}$.

As avaliações de massa seca da parte aérea e das raízes foram realizadas aos 10 dias após a emergência das plantas, coletando-se as plantas presentes em um metro linear por parcela. As análises visuais de fitointoxicação foram realizadas aos 3, 7, 15, 30 dias após a emergência das plantas, por meio de uma escala percentual de notas, em que zero representava nenhum controle e $100 \%$ o controle total das plantas (SOCIEDADE..., 1995). As avaliações foram iniciadas no momento em que as testemunhas sem tratamento químico (herbicida ou protetor) apresentavam uma emergência acima de $70 \%$.

Tabela 1 - Descrição dos tratamentos utilizados para a cultivar de trigo Ônix, aplicados em pré-emergência e no tratamento de sementes. Uberlândia, MG, 2006.

\begin{tabular}{|c|c|c|}
\hline \multicolumn{2}{|c|}{ Tratamentos principais } & \multirow{2}{*}{$\begin{array}{c}\text { Tratamentos secundários } \\
\text { Doses de fluxofenim } \\
\text { (mL por } 100 \mathrm{~kg} \text { sementes) }\end{array}$} \\
\hline $\begin{array}{c}\text { Doses S-metolachlor } \\
\quad\left(\text { g i.a. ha }{ }^{-1}\right)\end{array}$ & $\begin{array}{l}\text { Doses S-metolachlor } \\
\left(\mathrm{mL} \text { p.c. ha }{ }^{-1}\right)\end{array}$ & \\
\hline 0 & 0 & $\begin{array}{c}0 \\
40\end{array}$ \\
\hline 1.440 & 1.500 & $\begin{array}{c}0 \\
40\end{array}$ \\
\hline 2.880 & 3.000 & $\begin{array}{c}0 \\
40\end{array}$ \\
\hline
\end{tabular}

Tabela 2 - Tratamentos selecionados para a determinação da atividade da GST na cultivar de trigo Ônix. Uberlândia, MG, 2006.

\begin{tabular}{ccc}
\hline Doses S-metolachlor (g i.a. ha $\left.{ }^{-1}\right)$ & Doses S-metolachlor (mL p.c. ha $\left.{ }^{-1}\right)$ & Doses de fluxofenim (mL por $100 \mathrm{~kg}$ sementes) \\
\hline 0 & 0 & 0 \\
0 & 0 & 40 \\
1.440 & 1.500 & 0 \\
1.440 & 1.500 & 40 \\
\hline
\end{tabular}

Tabela 3 - Fitotoxicidade do herbicida S-metolachlor ao trigo Ônix tratado ou não com o fluxofenim, aos 3, 7, 15 e 30 dias após emergência. Uberlândia, MG, 2006.

\begin{tabular}{|c|c|c|c|c|c|c|c|c|}
\hline \multirow{3}{*}{$\begin{array}{l}\text { Doses do } \\
\text { herbicida } \\
\left(\text { g i.a. ha- }{ }^{-1}\right)\end{array}$} & \multicolumn{8}{|c|}{ \% Fitointoxicação } \\
\hline & \multicolumn{2}{|c|}{$3 \mathrm{DAA}$} & \multicolumn{2}{|c|}{$7 \mathrm{DAA}$} & \multicolumn{2}{|c|}{$15 \mathrm{DAA}$} & \multicolumn{2}{|c|}{$30 \mathrm{DAA}$} \\
\hline & $\operatorname{com}^{1}$ & $\operatorname{sem}^{1}$ & $\operatorname{com}^{1}$ & $\operatorname{sem}^{1}$ & $\operatorname{com}^{1}$ & $\operatorname{sem}^{1}$ & $\operatorname{com}^{1}$ & $\operatorname{sem}^{1}$ \\
\hline 0 & $0,00 \mathrm{Aa}$ & $0,00 \mathrm{Aa}$ & $0,00 \mathrm{Aa}$ & $0,00 \mathrm{Aa}$ & $0,00 \mathrm{Aa}$ & $0,00 \mathrm{Aa}$ & $0,00 \mathrm{Aa}$ & $0,00 \mathrm{Aa}$ \\
\hline 1.440 & $0,00 \mathrm{Aa}$ & $53,33 \mathrm{Bb}$ & $10,33 \mathrm{Ba}$ & $68,33 \mathrm{Bb}$ & $27,66 \mathrm{Ba}$ & $85,00 \mathrm{Bb}$ & $6,00 \mathrm{Ba}$ & $80,00 \mathrm{Bb}$ \\
\hline 2.880 & $11,66 \mathrm{Ba}$ & $78,33 \mathrm{Cb}$ & $25,00 \mathrm{Ca}$ & $89,33 \mathrm{Cb}$ & $63,33 \mathrm{Ca}$ & $95,00 \mathrm{Cb}$ & $33,33 \mathrm{Ca}$ & $93,33 \mathrm{Cb}$ \\
\hline F Herb. $(\mathrm{H})$ & \multicolumn{2}{|c|}{$260,23^{* *}$} & \multicolumn{2}{|c|}{$413,41^{* *}$} & \multicolumn{2}{|c|}{$609,93^{* *}$} & \multicolumn{2}{|c|}{$397,95^{* *}$} \\
\hline F Prot. $(\mathrm{P})$ & \multicolumn{2}{|c|}{$2.592,00 * *$} & \multicolumn{2}{|c|}{$2.322,22 * *$} & \multicolumn{2}{|c|}{$599,07^{* *}$} & \multicolumn{2}{|c|}{$1.016,38^{* *}$} \\
\hline F HXP & \multicolumn{2}{|c|}{$672,00^{* *}$} & \multicolumn{2}{|c|}{$585,22^{* *}$} & \multicolumn{2}{|c|}{$187,13^{* *}$} & \multicolumn{2}{|c|}{$262,42 * *$} \\
\hline $\mathrm{CV}(\%)$ & \multicolumn{2}{|c|}{7,0} & \multicolumn{2}{|c|}{5,6} & \multicolumn{2}{|c|}{5,7} & \multicolumn{2}{|c|}{8,4} \\
\hline d.m.s. & \multicolumn{2}{|c|}{3,33} & \multicolumn{2}{|c|}{3,59} & \multicolumn{2}{|c|}{5,14} & \multicolumn{2}{|c|}{5,94} \\
\hline
\end{tabular}

Herb. = Herbicida;

Prot. = Protetor;

${ }^{1}$ adição ou não do protetor fluxofenim;

**significativo ao nível de $1 \%$ de probabilidade;

Médias seguidas de mesma letra, minúscula na linha e maiúscula na coluna, não diferem estatisticamente entre si pelo teste $\mathrm{t}(\mathrm{p}>0,05)$. 
As amostras da parte aérea das plantas de cada unidade experimental do experimento foram coletadas aos 15 dias após a aplicação dos tratamentos e 10 dias após a emergência das plantas, quando estas apresentavam entre 2 a 4 folhas totalmente expandidas para a determinação da atividade da Glutationa S-transferase (GST). Apenas alguns tratamentos foram selecionados para essa etapa e estão descritos na Tabela 2.

Após a coleta das plântulas, as amostras da parte aérea foram lavadas com água destilada e secas superficialmente com folhas de toalhas de papel absorvente. As amostras de $1 \mathrm{~g}$ foram acondicionadas em sacos plásticos devidamente etiquetados e embaladas em papel alumínio. Em seguida, essas amostras foram congeladas em nitrogênio líquido $\left(-190^{\circ} \mathrm{C}\right)$ e armazenadas em freezer sob temperatura de $-85^{\circ} \mathrm{C}$ para posterior determinação da GST. Foram utilizadas 12 repetições por tratamento.

Para extração da GST foi utilizado o método proposto por EKLER et al. (1993), a atividade da enzima
GST foi determinada de acordo com método proposto por Wu et al. (1996) e o coeficiente de extinção molar de 9,6 mmol cm-1 (HABIG; JACOBY, 1981) foi usado para calcular a atividade da enzima. A atividade

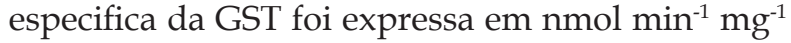
de proteína. O conteúdo de proteína solúvel total extraível no tampão utilizado na extração da GST foi estimado pelo método de Lowry et al. (1951). Foi utilizada albumina sérica bovina (BSA) como proteína padrão. As leituras de absorbância foram realizadas em espectrofotômetro, no comprimento de onda de $660 \mathrm{~nm}$.

O delineamento experimental adotado para esta etapa do trabalho foi o inteiramente casualizado em arranjo fatorial $2 \times 2$, correspondendo a 2 doses do herbicida ( 0 e $1.500 \mathrm{~mL} \mathrm{ha}^{-1}$ ) e 2 doses do protetor (0 e $40 \mathrm{~mL}$ por $100 \mathrm{~kg}$ sementes). Todos os resultados obtidos neste estudo foram submetidos à análise de variância pelo teste $\mathrm{F}(\mathrm{p}>0,05)$ e as médias dos tratamentos comparadas pelo teste $t$ de Student $(\mathrm{p}>0,05)$.

Tabela 4 - Valores de massa seca da parte aérea e raízes da cultivar de trigo Ônix, tratada ou não com o protetor fluxofenim, aos 10 dias após a emergência. Uberlândia, MG. 2006.

\begin{tabular}{|c|c|c|c|c|}
\hline \multirow{2}{*}{ Dose do herbicida (g i.a. ha-1) } & \multicolumn{2}{|c|}{ Parte Aérea (g) } & \multicolumn{2}{|c|}{ Raiz (g) } \\
\hline & c/ protetor & s/ protetor & c/ protetor & $\mathrm{s} /$ protetor \\
\hline 0 & a $0,88 \mathrm{~A}$ & a $0,84 \mathrm{~A}$ & $1,17 \mathrm{~A}$ & $1,12 \mathrm{~A}$ \\
\hline 1.440 & a $0,71 \mathrm{AB}$ & b 0,28 B & $0,62 \mathrm{~B}$ & $0,57 \mathrm{~B}$ \\
\hline 2.880 & a $0,61 \quad B$ & b 0,37 B & $0,77 \mathrm{~B}$ & $0,69 \mathrm{~B}$ \\
\hline F Herb. (H) & \multicolumn{2}{|c|}{$224,96^{* *}$} & \multicolumn{2}{|c|}{$16,573 * *$} \\
\hline F Prot. $(\mathrm{P})$ & \multicolumn{2}{|c|}{$185,11^{* *}$} & \multicolumn{2}{|c|}{$0,158^{\text {ns }}$} \\
\hline F HXP & \multicolumn{2}{|c|}{$41,58^{* *}$} & \multicolumn{2}{|c|}{$0,003^{\text {ns }}$} \\
\hline $\mathrm{CV}(\%)$ & \multicolumn{2}{|c|}{18,9} & \multicolumn{2}{|c|}{41,1} \\
\hline d.m.s. & \multicolumn{2}{|c|}{0,232} & \multicolumn{2}{|c|}{0,675} \\
\hline
\end{tabular}

Herb. = Herbicida;

Prot. = Protetor;

** significativo ao nível de $1 \%$ de probabilidade;

ns não significativo;

Médias seguidas de mesma letra minúscula na linha, e maiúscula na coluna, não diferem estatisticamente entre si pelo teste $t(p>0,05)$.

Tabela 5 - Atividade da enzima glutationa S-transferase na parte aérea de plantas de trigo, após o tratamento de sementes com o protetor fluxofenim e submetidas ao herbicida S-metolachlor. Uberlândia, MG. 2006.

\begin{tabular}{ccc}
\hline \multirow{2}{*}{ Doses de S-metolachlor (g i.a. ha-1 $)$} & \multicolumn{2}{c}{ Atividade de GST (nmol min $\mathrm{mg}^{-1}$ de proteína) } \\
\cline { 2 - 3 } & c/ protetor & s/ protetor \\
\hline 0 & 5,24 & 5,59 \\
1.440 & 7,98 & 4,72 \\
\hline F Herb. (H) & & $0,64^{\mathrm{ns}}$ \\
F Prot. (P) & $1,57^{\mathrm{ns}}$ & $2,43^{\mathrm{ns}}$ \\
F HXP & 68,29 \\
\hline CV $(\%)$ & & \\
\hline
\end{tabular}

Herb. $=$ Herbicida;

Prot. = Protetor;

$\mathrm{ns}^{\mathrm{n}}$ não significativo. 


\section{RESULTADOS E DISCUSSÃO}

Observa-se que o tratamento das sementes da cultivarÔnix apenas com ofluxofenimnão ocasionou nenhum tipo de injúria às plantas de trigo durante o período avaliado (Tabela 3). Aos $3 \mathrm{DAE}$, observa-se que as doses aplicadas do herbicida causaram danos visuais acima de $50 \%$ nas subparcelas que não receberam tratamento de sementes. A dose de $1.440 \mathrm{~mL}$ i.a. ha $^{-1}$ aos 30 DAE chegou a proporcionar níveis de até $80 \%$ de injúria. O S-metolachlor não é registrado para a cultura do trigo. Sua absorção dá-se predominantemente pelo hipocótilo das gramíneas quando estas entram em contato com a camada de solo onde se encontra o produto, sendo que os sintomas de fitointoxicação caracterizam-se pelo intumescimento dos tecidos, enrolamento do caulículo nas monocotiledôneas, necrose e morte das plantas (WEED..., 1994). As plântulas que emergem apresentam folhas retorcidas, mal formadas e com coloração predominantemente verde-escura. As folhas de gramíneas podem não emergir dos coleóptilos ou ficarem comprimidas no cartucho, não se desenrolam e nem se expandem normalmente (WEED..., 1994). Tais sintomas foram comuns nos tratamentos que não tiveram a presença do protetor nas sementes.

Nota-se, também, que houve interação significativa entre o tratamento de sementes com o protetor e as doses de herbicida, sendo que a dose utilizada do protetor nas sementes reduziu significativamente os sintomas visuais de injúria quando comparada àquelas sem o tratamento de sementes, ambas com aplicação do herbicida. Mesmo com a redução dos sintomas visuais de injúria nos tratamentos com a presença do protetor, a utilização da dose de 1.440 $\mathrm{mL}$ i.a. ha ${ }^{-1}$ de S-metolachlor a partir de 7 DAE diferenciou-se da testemunha, tendo atingido os valores mais elevados de injúria aos 15 DAE. Aos 30 DAE, a redução da porcentagem visual de fitointoxicação pode ser atribuída a um maior perfilhamento das plantas de trigo.

Na Tabela 4 estão apresentados o acúmulo de massa seca da parte aérea e das raízes coletados aos 10 dias após o início da emergência das plantas. Não se verificou diferença significativa quando se comparou as testemunhas sem aplicação de herbicida (com e sem protetor) quanto ao acúmulo de massa seca de parte aérea.

A utilização ou não do protetor no tratamento de sementes foi defundamental importância em relação ao acúmulo de massa seca quando as plantas foram submetidas à aplicação do S-metolachlor, sendo os valores de massa seca da parte aérea e raiz mais elevados nas parcelas que receberam o tratamento de sementes. Para a dose de $1.440 \mathrm{~mL}$ i.a. ha ${ }^{-1}$, o tratamento de sementes proporcionou acúmulo de até $70 \%$ a mais de matéria seca da parte aérea quando comparado a parcela sem tratamento de sementes. As plantas de trigo tratadas com protetor e que receberam a dose de $2.880 \mathrm{~mL}$ i.a. ha ${ }^{-1}$ apresentaram acúmulo de massa seca da parte aérea de aproximadamente $30 \%$ menor quando comparado ao da testemunha (com aplicação de protetor) e, para as parcelas que não receberam o protetor, a diferença em relação a testemunha apresentou um decréscimo de $65 \%$.

Cataneo (2001), testando o herbicida fenoxapropp-ethyl com o protetor mefenpyr-diethyl em seis diferentes cultivares de trigo, também obteve resultados com menores valores de acúmulo de massa verde das plantas quando os diferentes cultivares de trigo foram submetidos à aplicação do herbicida sem utilização do protetor.

Na Tabela5 estão representados, respectivamente, os valores correspondentes a atividade da GST em trigo, quando as sementes receberam o tratamento com o protetor e foram submetidas ou não ao tratamento com o herbicida S-metolachlor, comparados com a testemunha sem o protetor e sem o herbicida.

Apesar dos dados apresentados não serem significativamente diferentes, os resultados em termos de médias demonstraram que houve um efeito entre o tratamento das sementes de trigo com o protetor fluxofenim e a aplicação do herbicida S-metolachlor em pré-emergência na atividade da GST.

Esse efeito foi o aumento de $69 \%$ quando comparado a parcela que não recebeu o tratamento de sementes e pode ser considerado comoum dos fatores pelos quais as plantas de trigo demonstraram ser mais tolerantes a aplicação do herbicida S-metolachlor.

Apesar deste aumento observado na atividade da GST, os níveis não foram ainda suficientes para prover as plantas de trigo de uma total seletividade. Essa afirmação pode ser baseada nas notas de fitointoxicação (Tabela 3) observadas a partir dos 7 dias após a aplicação do herbicida, no qual se tem valores maiores de injúria que podem ser considerados prejudiciais ao desenvolvimento normal e expressão do potencial da cultura.

Para as plantas que receberam somente o tratamento de sementes observa-se uma pequena redução de $6 \%$ na atividade da GST, enquanto que na parcela não tratada com o protetor onde foi aplicado o herbicida em pré-emergência, as plantas mostraram uma redução de $16 \%$ quando comparada a testemunha sem tratamentos aos 10 dias após a emergência das plântulas.

O protetor de sementes testado neste estudo foi capaz de gerar um acréscimo, mesmo não sendo significativo, na atividade de GST para a cultura de trigo. Contudo, é importante ressaltar que os poucos dados de literatura encontrados sobre o protetor fluxofenim demonstram também a alta afinidade existente entre a sua molécula e a do herbicida S- 
metolachlor (Davies; CASeley, 1999; Hatzios, 1983; 2000; PARKER, 1983).

\section{CONCLUSÕES}

O tratamento das sementes do trigo Ônix não afeta o desenvolvimento inicial da cultura, sendo que a utilização do fluxofenim na cultivar de trigo Ônix propicia uma maior tolerência ao herbicida S-metolachlor;

Visualmente, a seletividade proporcionada pelo protetor não pode ser considerada aceitável, portanto, há necessidade de novos estudos quanto a dose do protetor;

O tratamento de sementes com fluxofenim aumenta a atividade da GST nas plântulas do trigo sob aplicação do herbicida S-metolachlor.

\section{REFERÊNCIAS}

CATANEO, A.C. Estudos fisiológicos e bioquímicos da ação do mefenpyr-diethyl na desintoxicação do herbicida fenoxaprop-p-ethyl em cultivares de trigo (Triticum aestivum L.). 2001. 88f. Tese (Livre Docência em Ciências Biológicas-Área de Bioquímica) - Instituto de Biociências, Universidade Estadual Paulista, Botucatu, 2001.

CATANEO, A.C.; DESTRO, G.F.G.; FERREIRA, L.C.; CHMMA, H.L.; SOUSA, D.C.F. Atividade da glutationa S-transferase na degradação do herbicida glyphosate em plantas de milho (Zea mays). Planta Daninha, v.21, n.2, p.307-312, 2003.

DAVIES, J.; CASELEY, J.C. Herbicide protetors: a review. Pesticide Science, v.55, n.11, p.1043-1058, 1999.

DIAS, N.M.P.; CHRISTOFFOLETI, P.J.; TORNISIELO, V.L. Identificação taxonômica de espécies de capim-colchão infestantes da cultura da cana-de-açúcar no Estado de São Paulo e eficácia de herbicidas no controle de Digitaria nuda. Bragantia, v.64, n.3, p.389-396, 2005.

EKLER, Z.; DUTKA, F.; STEPHENSON, G.R. Protetor effects on acetochlor toxicity uptake, metabolism and Glutathione S-transferase activity in maize. Weed Research, v.54, p.96-109, 1993.

FARAGO, S.; BRUNOLD, C. Regulation of assimilatory sulfate reduction by herbicide safeners in Zea mays $\mathrm{L}$. Plant Physiology, v.94, p.1808-1812, 1990.

HABIG, W.H.; JAKOBY, W.B. Assays for differentiation of glutathione S-transferases. Methods in Enzymology, v.77, p.398-405, 1981.

HATZIOS, K.K. Herbicides antidotes: development, chemistry and mode of action. Advances in Agronomy, v.36, p.265-316, 1983.
HATZIOS, K.K. Herbicide protetors and synergists. In: ROBERTS, T. (Ed.). Metabolism of agrochemicals in plants. Chicester: Wiley, 2000. p.259-294.

HESS, F.D.; WELLER, S.C. Principles of selectivity weed control with herbicides. Herbicides action course. Indiana: Purdue University, 2000. p.112-134.

JABLONKAI, I.; HATZIOS, K.K. Role of glutathione and glutathione S-transferase in the selectivity of acetochlor in maize and wheat. Pesticide Biochemistry and Physiology, v.41, p.221-231, 1991.

KARAM, D. Características do herbicida S-metolachlor nas culturas de milho e sorgo. Circular Técnica do Centro Nacional de Pesquisa de Milho e Sorgo, n.36, p.65-67, 2003.

KREUZ, K.; TOMMASINI, R.; MARTINOIA, E. Old enzymes for a new job: herbicide detoxification in plants. Plant Physiology, v.111, p.349-353, 1996.

LOWRY, O.H.; ROSEBROUGH, N.J.; FARR, A.L. Protein measurement with Folin-phenol reagent. Journal of Biological Chemistry, v.193, p.265-275, 1951.

MANNERVIK, B.; DANIELSON, U.H. Glutathione S-transferase: structure and catalytic activity. Critical Reviews in Biochemistry and Molecular Biology, v.23, p.283337, 1988.

MAUCH, F.; DUDLER, R. Differential induction of distinct glutathione S-transferase of wheat by xenobiotics and by pathogenic attack. Plant Physiology, v.102, p.1193-1201, 1993.

NEMAT ALLA, M.M.N.; BADAWI, A.M.; HASSAN, N.M.; BASTAWISY, Z.M.E.; BADRAN, E.G. Induction of Glutathione and Glutathione-associated Enzymes in Butachlor-tolerant Plant Species. American Journal of Plant Physiology, v.3, n.2, p.195-205, 2007.

NEMAT ALLA, M.M.N.; BADAWI, A.M.; HASSAN, N.M.; BASTAWISY, Z.M.E.; BADRAN, E.G. Herbicide tolerance in maize is related to increased levels of glutathione and glutathione-associated enzymes. Acta Physiologiae Plantarum, v.30, n.3, p.371-379, 2008.

PARKER, C. Herbicide antidotes. A review. Pesticide Science, v.14, p.40-48, 1983.

PITELLI, R.A. Competição e controle das plantas daninhas em áreas agrícolas. Série Técnica IPEF, v.4, p.1-24, 1987.

RIECHERS, D.E.; YANG, K.; IRZYK, G.P.; JONES, S.S.; FUERST, E.P. Variability of glutathione S-transferase levels and dimethanamid tolerance in protetor-treated wheat and wheat relatives. Pesticide Biochemistry and Physiology, v.56, p.88-101, 1996.

SOCIEDADE BRASILEIRA DA CIÊNCIA DAS PLANTAS DANINHAS. Procedimentos para instalação, avaliação 
e análise de experimentos com herbicidas. Londrina: SBCPD, 1995. 42p.

SYNGENTA. Concep III: Herbicide antidote. North Carolina: Syngenta Crop Protection, 2002. 5p. Disponível em: <http:/ / www.syngentacropprotection.com/pdf/ labels/SCP101L5F0302.pdf>. Acesso em: 24 abr. 2011.

TAL, A.; ROMANO, M.L.; STEPHENSON, G.R. Glutayhione conjugation: a detoxification pathway for fenoxaprop-ethyl in barley, crabgrass, oat and wheat. Pesticide Biochemistry and Physiology, v.46, p.190-99, 1993.

VARGAS, L.; BIANCHI, M.A.; RIZZARDI, M.A.; AGOSTINETTO, D.; DAL MAGRO, T. Buva (Conyza bonariensis) resistente ao glyphosate na região sul do Brasil. Planta Daninha, v.25, n.3, p.573-578, 2007.

WEED SCIENCE SOCIETY OF AMERICA. Herbicide handbook. 7.ed. Champaign: WSSA, 1994.352p.

WU, J.; OMOKAWA, H.; HATZIOS, K.K. Glutathione S-transferase activity in unsafened and fenclorinsafened-rice (Oryza sativa). Pesticide Biochemistry and Physiology, v.54, p.220-229, 1996.

Recebido em 19/2/10

Aceito em 27/4/11 